\title{
Influence of Root Rotation on Delamination Fracture Toughness of Composites
}

\author{
V. Alfred Franklin,, T. Christopher, ${ }^{2}$ and B. Nageswara Rao ${ }^{3}$ \\ ${ }^{1}$ Faculty of Mechanical Engineering, Sardar Raja College of Engineering, Alangulam, Tirunelveli 627808, India \\ ${ }^{2}$ Faculty of Mechanical Engineering, Government College of Engineering, Tirunelveli 627007, India \\ ${ }^{3}$ Faculty of Mechanical Engineering, School of Mechanical and Civil Sciences, KL University, Green Fields, \\ Vaddeswaram 522502, India
}

Correspondence should be addressed to V. Alfred Franklin; frank_vin@yahoo.com

Received 20 May 2014; Revised 11 September 2014; Accepted 25 September 2014; Published 20 October 2014

Academic Editor: Nicolas Avdelidis

Copyright (C) 2014 V. Alfred Franklin et al. This is an open access article distributed under the Creative Commons Attribution License, which permits unrestricted use, distribution, and reproduction in any medium, provided the original work is properly cited.

Large deviations have been observed while analysing composite double cantilever beam (DCB) specimens assuming each cracked half as a simple cantilever beam. This paper examines the effect of rotational spring stiffness $(K)$ on the critical fracture energy $\left(G_{I C}\right)$ considering nonzero slope at the crack-tip of the DCB specimen by modelling each cracked half as the spring-hinged cantilever beam. The critical load estimates of DCB specimens from $G_{I C}$ are found to be in good agreement with in-house and existing test results of different composite material systems.

\section{Introduction}

The lightweight carbon fiber-reinforced composite (having high stiffness, strength, fatigue and impact resistance, thermal conductivity, and corrosion resistance) is found to be more economical for commercial aircraft [1]. It has become the primary material in many aircraft components (namely, fuselage, wings, and empennage components) [2]. The high strength and stiffness laminated composites in aircraft and spacecraft structures possess different properties in different directions due to their anisotropic nature. The excellent properties of composites can be utilized when the loading direction coincides with the reinforced direction. In general, the loading is multidirectional for many complex structures, which may initiate delamination and matrix cracking causing loss of structural integrity. Testing of thin skin stiffened panels of aircraft fuselage experiences bond failure at the tip of the frame flange [3]. The interlaminar fracture toughness (or the critical strain energy release rate at the onset of crack or damage propagation) is an important fracture property to be evaluated utilizing the fracture mechanics principles.
Walker et al. $[4,5]$ have examined the tension fracture of laminates for transport fuselage, whereas Wang et al. [6] have utilized the R-curve method for the residual strength evaluation of damaged composite fuselage panel. Research and developmental activities are going on the design of the lightweight composite aircraft to sustain the discrete source of damage (see Figure 1).

The mode-I fracture energy evaluation relies heavily on the interpretation of fracture data, namely, the loaddisplacement $(P-\delta)$ records of specimens containing artificially created crack like defects. The double cantilever beam (DCB) test is widely used for evaluation of the mode-I fracture energy originally developed for studying the fracture of adhesively bonded joints [7]. Hashemi et al. [8] have evaluated the fracture energy of carbon/PEEK and carbon/epoxy composites. A good agreement is noticed between the fracture energy values from the area and compliance methods, but there is a poor agreement with those values obtained from the "load" and "displacement" methods based on simple beam theory. Several factors (namely, errors in the measurement of crack length and displacement, shear 


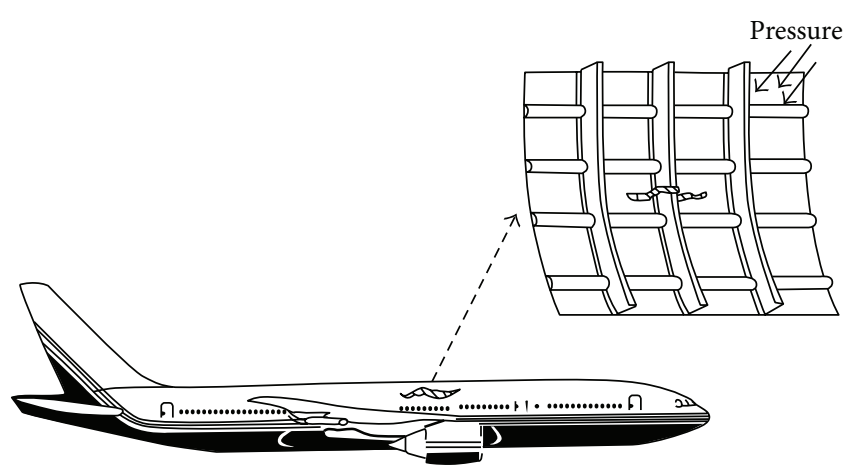

FIGURE 1: Fuselage panel with discrete source damage [6].

correction, and large displacement correction) are being considered to account for these discrepancies. None of these possible errors are significant enough to eliminate the discrepancies and correct the analytical method. Rao and Acharya $[9,10]$ have proposed a procedure for small as well as large deflections considering nonzero slope at the crack-tip of the DCB specimens.

Motivated by the work of the above researchers, this paper examines the effect of rotational spring stiffness on the critical strain energy release rate $\left(G_{I C}\right)$ useful for accurate failure load evaluation of delaminated composites. The critical load estimates of DCB specimens from $G_{I C}$ are found to be in good agreement with in-house and existing test data of different composites.

\section{Theoretical Background}

Composite laminates are linear elastic materials. The interlaminar fracture of composites can be dealt with the linear elastic fracture mechanics (LEFM). The double cantilever beam (DCB) test specimens are being used for mode-I fracture of unidirectional composites. Fracture energy or the critical strain energy release rate $\left(G_{I C}\right)$ evaluation in the opening mode (mode-I) for a composite depends on the interpretation of fracture data. Normally, the fracture data consists of a load-displacement $(P-\delta)$ record for cracked specimens. The two different LEFM approaches are the area and compliance methods. According to the area method, the released energy due to crack extension can be evaluated by using Irwin's formula for the critical energy release rate $\left(G_{I C}\right)$ [11, 12]:

$$
G_{I C}=-\frac{1}{B} \frac{\partial \prod}{\partial a},
$$

where $\prod$ is the total energy of the structure and $B$ and $a$ are the width and length of the crack, respectively. For the elastic body the critical energy release rate can be determined by the formula

$$
G_{I C}=\frac{\Delta U}{B \Delta a}, \quad \Delta U=\frac{1}{2}\left(P_{1} \delta_{2}-P_{2} \delta_{1}\right)
$$

where $U$ is the strain energy, $P_{1}$ and $\delta_{1}$ are the load and the displacement at crack length $a$, and $P_{2}$ and $\delta_{2}$ are the respective values at crack length $a+\Delta a$.

Since the strain energy for linear response is $U=P \delta / 2$ and $\prod=-U$, the energy release rate in (1) can be expressed through the compliance $[11,12]$

$$
G_{I C}=-\frac{1}{B} \frac{\partial \prod}{\partial a}=\frac{1}{B} \frac{\partial U}{\partial a}=\frac{P_{\mathrm{cr}}^{2}}{2 B} \frac{\partial C}{\partial a},
$$

where $P_{\text {cr }}$ is the critical load at which crack growth is observed, $C=\delta / P$ is the compliance, and $\delta$ is the displacement. In order to evaluate $G_{I C}$ the compliance must be calculated by using the experimental data, that is, the measurements of the load and displacement at different crack length.

For the DCB test specimen the compliance calculated by the linear beam theory is given by $[11,12]$

$$
C=\frac{\delta}{P_{\mathrm{cr}}}=\frac{2}{3} \frac{a^{3}}{E_{11} I},
$$

where $E_{11}$ is modulus of elasticity in the direction of beam axis, $I=B h^{3} / 12$ is the area moment, and $h$ is half the thickness of the DCB specimen. Using (4) in (3), the critical energy release rate for DCB test can be calculated by

$$
G_{I C}=\frac{3 P_{\mathrm{cr}} \delta}{2 B a} .
$$

Equation (5) can be used for mean value of $G_{I C}$ by using the data reduction with the least square technique. The analytical formula (5), which is based on the simple beam theory, can be corrected by using the fracture data. In Berry method, the compliance is approximated by a power-law:

$$
C=k a^{n}
$$

where $n$ and $k$ are determined experimentally. Using (6) in (3), one can find

$$
G_{I C}=\frac{P_{\mathrm{cr}}^{2}}{2 B} k n a^{n-1}=\frac{n P_{\mathrm{cr}} \delta}{2 B a} .
$$

According to beam theory, the parameter $n$ should be 3, but from the fracture data, another value of this parameter can be obtained. It is noted that different data reduction methods give different $G_{I C}$ values, because, in the linear beam theory, some effects are not taken into account: the rotation and deflection at the crack-tip, the large displacements present in the test specimen, and stiffening effects due to the presence of the bonded end blocks. To compensate for the rotation of the adherends at the crack-tip and the flexibility of the adhesive layer, the crack length is increased with correction term $\chi$. Accordingly $a$ is replaced with $a+\chi$ in (4). The compliance $C$ is proportional to $(a+\chi)^{3}$. It should be noted that $\chi$ should be positive. Thus, in a plot of $\sqrt[3]{C}$ versus the crack length $a$, the correction $\chi$ is found as the intercept of the extrapolation of experimental values to $\sqrt[3]{C}=0$. This procedure is being followed in the modified beam analysis. 


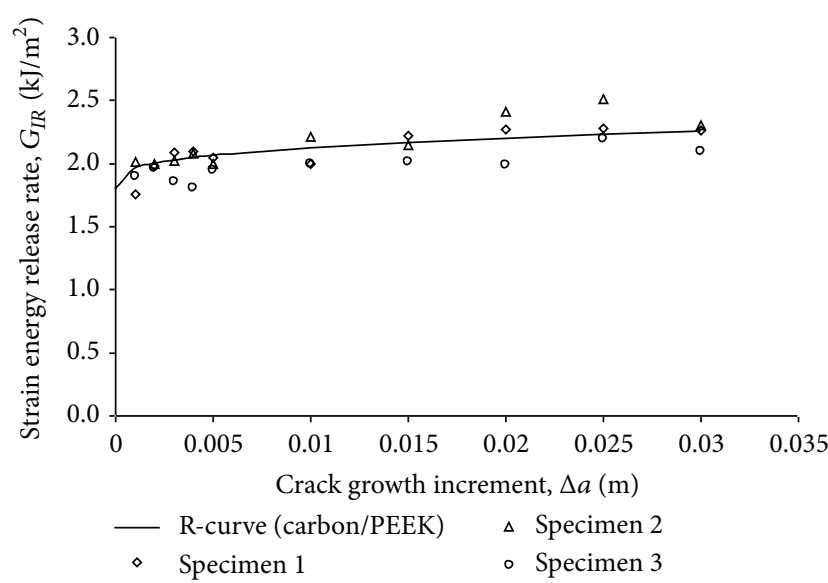

FIGURE 2: R-curve $\left(G_{I R}=1798+1286(\Delta a)^{0.29}\right)$ of DCB specimens made of carbon/PEEK.

Analysis of experimental results can also be performed by the finite element method. For calculating the energy release rates the modified virtual crack closure integral (MVCCI) can be used [12].

Hashemi et al. [8] have found good agreement between the values of $G_{I C}$ from the area and compliance methods. They noticed poor agreement with those values of $G_{I C}$ from the load and displacement methods based on simple beam theory. Rao and Acharya $[9,10]$ have considered nonzero slope at the crack-tip of the DCB specimen by modelling each cracked half as the spring-hinged cantilever beam and provided the compliance as

$$
C=\frac{\delta}{P}=\frac{2}{3} \frac{a^{3}}{E_{11} I}+\frac{2}{K} a^{2}
$$

Here $K$ is the rotational spring constant. For the case of infinitely large support stiffness (i.e., $K \rightarrow \infty$ ), (8) reduces to (4) for the case of a simple beam. In reality, infinitely large support stiffness at the crack-tip of the DCB specimen will not exist. For a realistic analysis, the rotational stiffness of the support has to be taken. The rotational spring constant $K$ in (8) has to be obtained from (8) by substituting the measured value of load and displacement for the measured crack size of the DCB specimen.

Eliminating $K$ in (8), the fracture toughness can be evaluated from the fracture data as $[13,14]$

$$
G_{I C}=\frac{1}{n} \sum_{i=1}^{n}\left(\frac{P_{\mathrm{cr}}^{2} a^{2}}{3 B E_{11} I}+\frac{P_{\mathrm{cr}} \delta_{\mathrm{cr}}}{B a}\right)_{i}
$$

The critical load $\left(P_{\mathrm{cr}}\right)$ is evaluated from

$$
P_{\mathrm{cr}}=\sqrt{G_{I C}\left\{\frac{a^{2}}{B E_{11} I}+\frac{2 a}{B K}\right\}^{-1}} .
$$

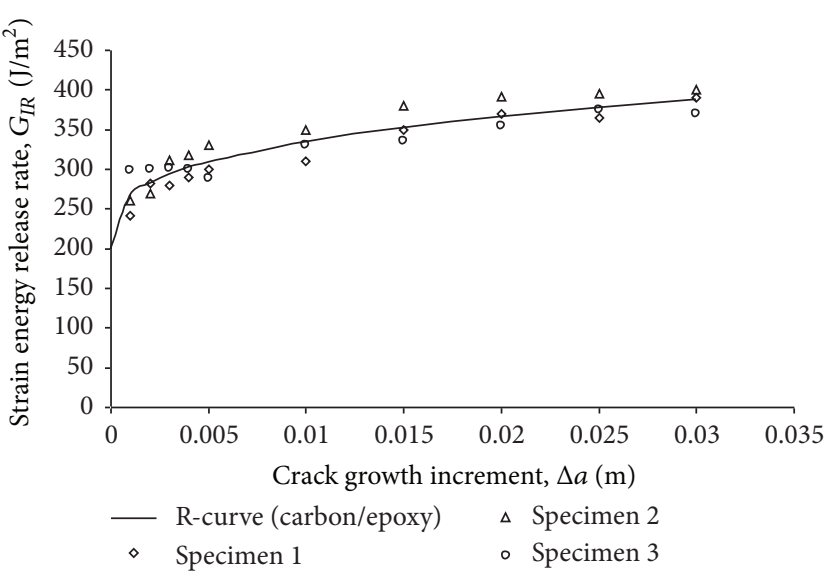

FIGURE 3: R-curve $\left(G_{I R}=199+540(\Delta a)^{0.3}\right)$ of DCB specimens made of carbon/epoxy.

The rotational spring constant $(K)$ in $(10)$ is obtained from the fracture data as

$$
\frac{1}{K}=\left\{\sum_{i=1}^{n}\left(\frac{\delta_{\mathrm{cr}}}{P_{\mathrm{cr}}}-\frac{2}{3} \frac{a^{3}}{E_{11} I}\right)_{i} a_{i}^{2}\right\}\left\{\sum_{i=1}^{n} 2 a_{i}^{4}\right\}^{-1} .
$$

The mode-I delamination fracture toughness $\left(G_{I C}\right)$ is evaluated considering the fracture data of glass/epoxy [15]. Table 1 gives comparison of $G_{I C}$ values obtained from the modified beam analysis, compliance method, finite element method, Berry method, and the present approach based on the spring-hinged cantilever beam theory. The critical energy release rates $\left(G_{I C}\right)$ obtained from the different data reduction methods are in good agreement with each other.

\section{Experimentation}

Fracture toughness tests have been performed on the DCB specimens made of carbon/epoxy and carbon/PEEK composites. To create the initial crack in the composite specimens, a thin Teflon film (having $13 \mu \mathrm{m}$ thickness) is inserted during stacking. As per the ASTM standard D5528 [16], the optimum size of the DCB specimen should have 20 to $25 \mathrm{~mm}$ width, above $125 \mathrm{~mm}$ length, and 3 to $5 \mathrm{~mm}$ thickness. The DCB specimens of $130 \mathrm{~mm}$ length, $20 \mathrm{~mm}$ width, and $3 \mathrm{~mm}$ thickness are made from carbon/epoxy and $3.25 \mathrm{~mm}$ thick carbon/PEEK composites. Fracture toughness tests are valid only when the initial delamination length $\left(a_{0}\right)$ and the thickness $(2 h)$ of DCB specimens satisfy the following criteria [14]:

$$
a_{0} \leq 0.042 \sqrt{\frac{E_{11}(2 h)^{3}}{G_{I C}}}, \quad 2 h \geq 8.48 \sqrt{\frac{G_{I C} a_{0}^{2}}{E_{11}}} .
$$

The specimen surfaces are scrubbed with sand paper and cleaned thoroughly with acetone. To maintain good bonding, the base of aluminium piano hinge is scratched with file and cleaned with acetone. A thin layer of araldite adhesive is used 
TABLE 1: Comparison of mode-I delamination fracture toughness of glass/epoxy composite by different data reduction schemes.

\begin{tabular}{|c|c|c|c|c|c|c|c|}
\hline \multicolumn{3}{|c|}{ Test results [15] } & \multicolumn{5}{|c|}{ Critical energy release rate, $G_{I C}\left(\mathrm{~J} / \mathrm{m}^{2}\right)$} \\
\hline $\begin{array}{l}\text { Crack length, } \\
a(\mathrm{~mm})\end{array}$ & $P(\mathrm{~N})$ & $\delta(\mathrm{mm})$ & $\begin{array}{c}\text { Modified } \\
\text { beam analysis }\end{array}$ & $\begin{array}{c}\text { Compliance } \\
\text { method }\end{array}$ & $\begin{array}{c}\text { FEM } \\
\text { (linear analysis) }\end{array}$ & Berry method & Present (9) \\
\hline 33.45 & 38.93 & 3.54 & 234 & 229 & 229 & 244 & 244 \\
\hline 41.30 & 35.63 & 5.47 & 299 & 292 & 323 & 280 & 290 \\
\hline 50.80 & 31.63 & 8.93 & 355 & 348 & 381 & 332 & 343 \\
\hline 60.59 & 28.21 & 14.08 & 400 & 392 & 427 & 392 & 398 \\
\hline 70.33 & 25.11 & 19.42 & 424 & 418 & 453 & 413 & 423 \\
\hline 79.87 & 23.11 & 26.87 & 459 & 456 & 490 & 464 & 470 \\
\hline 89.29 & 21.6 & 35.03 & 495 & 498 & 532 & 505 & 512 \\
\hline 98.56 & 20.31 & 44.04 & 524 & 536 & 573 & 541 & 550 \\
\hline 107.80 & 19.16 & 53.14 & 548 & 569 & 607 & 563 & 577 \\
\hline 116.60 & 18.33 & 64.28 & 570 & 609 & 649 & 603 & 617 \\
\hline
\end{tabular}

Lay-up: $[0]_{22}, B=25 \mathrm{~mm}, 2 h=3 \mathrm{~mm}$, and $E=40.7 \mathrm{GPa}$.

TABLE 2: Critical load $P_{\text {cr }}$ and corresponding displacement $\delta_{\text {cr }}$ for the measured crack length of a DCB specimen made of unidirectional carbon/epoxy composite.

\begin{tabular}{|c|c|c|c|c|c|c|c|}
\hline \multicolumn{3}{|c|}{ Test results } & \multicolumn{5}{|c|}{ Present analysis } \\
\hline \multirow{2}{*}{$\begin{array}{l}\text { Crack length, } \\
a(\mathrm{~mm})\end{array}$} & \multirow{2}{*}{$P(\mathrm{~N})$} & \multirow{2}{*}{$\delta(\mathrm{mm})$} & \multirow{2}{*}{$\begin{array}{c}P_{\mathrm{cr}}(\mathrm{N}) \\
(10)\end{array}$} & \multirow{2}{*}{$\begin{array}{c}\delta_{\mathrm{cr}}(\mathrm{mm}) \\
(8)\end{array}$} & \multicolumn{2}{|c|}{$\%$ relative error in } & \multirow{2}{*}{$\begin{array}{l}P_{\max }, \\
(13)\end{array}$} \\
\hline & & & & & Load & Displacement & \\
\hline 51 & 41.92 & 5.15 & 41.55 & 4.86 & 0.88 & 5.53 & 43.14 \\
\hline 52 & 40.90 & 5.31 & 40.78 & 5.05 & 0.30 & 4.95 & 42.31 \\
\hline 53 & 39.74 & 5.48 & 40.04 & 5.24 & -0.75 & 4.40 & 41.51 \\
\hline 54 & 39.09 & 5.65 & 39.32 & 5.43 & -0.58 & 3.87 & 40.74 \\
\hline 55 & 38.71 & 5.82 & 38.63 & 5.63 & 0.20 & 3.37 & 40.00 \\
\hline 60 & 35.55 & 6.57 & 35.51 & 6.66 & 0.10 & -1.34 & 36.67 \\
\hline 65 & 31.97 & 7.74 & 32.86 & 7.78 & -2.77 & -0.57 & 33.85 \\
\hline 70 & 30.97 & 8.82 & 30.57 & 8.99 & 1.27 & -1.99 & 31.43 \\
\hline 75 & 27.44 & 9.97 & 28.59 & 10.29 & -4.19 & -3.15 & 29.33 \\
\hline 80 & 26.46 & 11.21 & 26.84 & 11.67 & -1.45 & -4.10 & 27.50 \\
\hline
\end{tabular}

Lay-up: $[0]_{24}, B=20 \mathrm{~mm}, 2 h=3 \mathrm{~mm}, a_{o}=50 \mathrm{~mm}, E=150 \mathrm{GPa}, K=425 \mathrm{Nm}$, and $G_{I C}=286.82 \mathrm{~J} / \mathrm{m}^{2}$.

for fixing of the piano hinge to the specimen, which is meant for application of the load. Proper care is taken while applying the araldite without covering the sides of Teflon insert. The maximum load anticipated during a DCB test is [17]

$$
P_{\max }=\frac{B}{a} \sqrt{\frac{G_{I C}(2 h)^{3} E_{11}}{96}} .
$$

Instron3367 universal testing machine is used for testing of specimens subjected to wedge loading under displacement control. The crosshead speed is set at $1 \mathrm{~mm} / \mathrm{min}$ to ensure steady crack propagation and ease of recording. The loaddisplacement $(P-\delta)$ history had been recorded by the computer. Specimen edges are coated with typewriter correction fluid and marking on the specimen started from the end of the insert to monitor the crack propagation. As per ASTM standards, the first five markings are made at an interval of
$1 \mathrm{~mm}$ and the rest at an interval of $5 \mathrm{~mm}$. The crack growth from the starter insert is observed through magnification lens and $P-\delta$ history.

Fracture data of carbon/epoxy and carbon/PEEK composites generated from DCB specimens and the values of $G_{I C}$ are presented in Tables 2 and 3. The relative error in critical load estimates is found to be less than $5 \%$, whereas it is less than $10 \%$ on displacement estimates. This demonstrates the accuracy of $G_{I C}$ evaluation utilizing (9). The rotational spring stiffness $(K)$ value for carbon/PEEK DCB specimens is found to be very large. Hence the critical load $\left(P_{\mathrm{cr}}\right)$ obtained from the present analysis is close to the value obtained from (13). The crack growth resistance curve (R-curve) for the two composites is generated from the fracture data and represented by the power-law: $G_{I R}=G_{0}+A(\Delta a)^{m}$. It is observed from Figures 2 and 3 that the critical fracture energy of carbon/PEEK is much higher than that of carbon/epoxy. 
TABLE 3: Critical load $P_{\text {cr }}$ and corresponding displacement $\delta_{\text {cr }}$ for the measured crack length of a DCB specimen made of unidirectional carbon/PEEK composite.

\begin{tabular}{|c|c|c|c|c|c|c|c|}
\hline \multicolumn{3}{|c|}{ Test results } & \multicolumn{5}{|c|}{ Present analysis } \\
\hline \multirow{2}{*}{$\begin{array}{l}\text { Crack length, } \\
a(\mathrm{~mm})\end{array}$} & \multirow{2}{*}{$P(\mathrm{~N})$} & \multirow{2}{*}{$\delta(\mathrm{mm})$} & \multirow{2}{*}{$\begin{array}{l}P_{\mathrm{cr}}(\mathrm{N}) \\
\quad(10)\end{array}$} & \multirow{2}{*}{$\begin{array}{c}\delta_{\mathrm{cr}}(\mathrm{mm}) \\
(8)\end{array}$} & \multicolumn{2}{|c|}{$\%$ relative error in } & \multirow{2}{*}{$\begin{array}{l}P_{\max }, \\
(13)\end{array}$} \\
\hline & & & & & Load & Displacement & \\
\hline 51 & 120.59 & 10.95 & 119.48 & 11.45 & 0.92 & -4.55 & 119.48 \\
\hline 52 & 119.14 & 11.07 & 117.18 & 11.91 & 1.65 & -7.57 & 117.18 \\
\hline 53 & 117.01 & 11.89 & 114.97 & 12.37 & 1.74 & -4.02 & 114.97 \\
\hline 54 & 115.06 & 12.72 & 112.84 & 12.84 & 1.93 & -0.94 & 112.84 \\
\hline 55 & 112.79 & 13.16 & 110.79 & 13.32 & 1.78 & -1.22 & 110.79 \\
\hline 60 & 104.44 & 14.77 & 101.56 & 15.85 & 2.76 & -7.32 & 101.56 \\
\hline 65 & 96.56 & 17.98 & 93.74 & 18.60 & 2.91 & -3.46 & 93.74 \\
\hline 70 & 89.80 & 20.00 & 87.05 & 21.58 & 3.06 & -7.90 & 87.05 \\
\hline 75 & 84.91 & 23.61 & 81.24 & 24.77 & 4.32 & -4.91 & 81.24 \\
\hline 80 & 76.98 & 26.72 & 76.17 & 28.18 & 1.05 & -5.45 & 76.17 \\
\hline
\end{tabular}

Lay-up: $[0]_{26}, B=20 \mathrm{~mm}, 2 h=3.25 \mathrm{~mm}, a_{o}=50 \mathrm{~mm}, E=129 \mathrm{GPa}, 1 / K \rightarrow 0$, and $G_{I C}=2012.26 \mathrm{~J} / \mathrm{m}^{2}$.
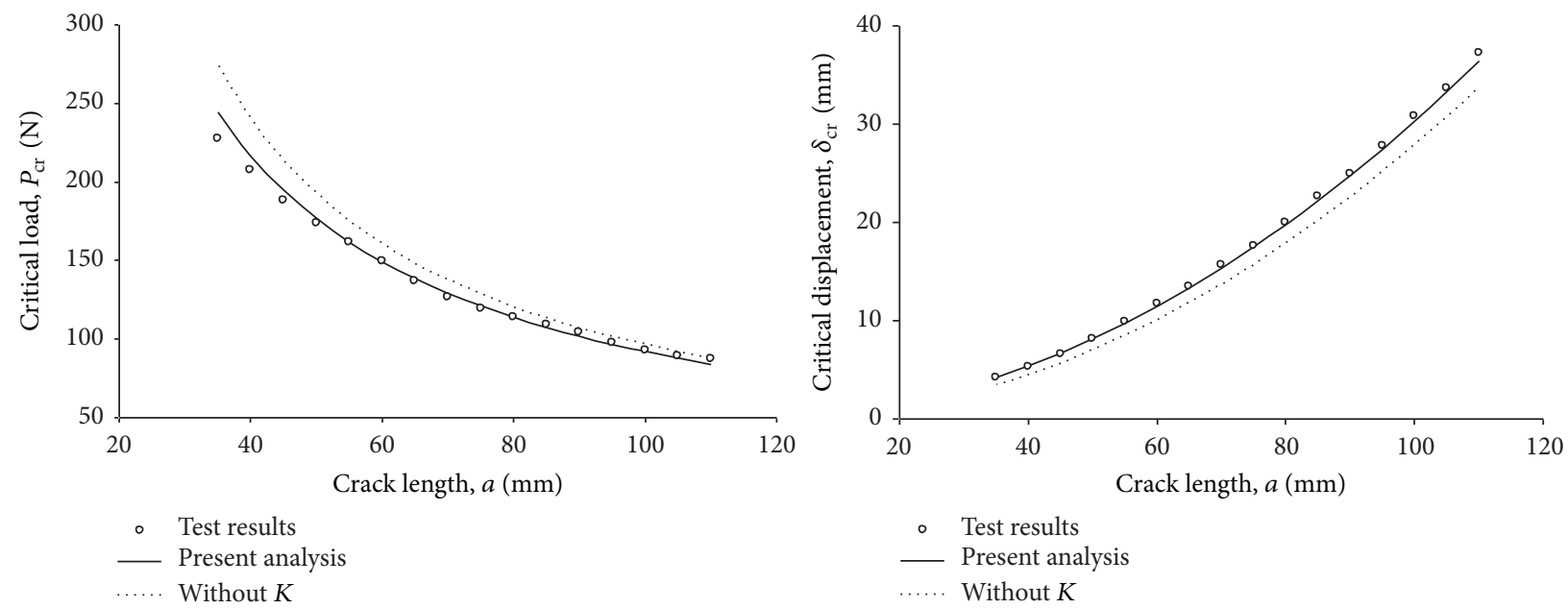

FIGURE 4: Comparison of experimental [8] and fracture analysis results of the critical load $\left(P_{\text {cr }}\right)$ and the corresponding displacement $\left(\delta_{\text {cr }}\right)$ with the crack length of unidirectional DCB specimens made of carbon/PEEK composites $(B=20 \mathrm{~mm}, 2 h=4.4 \mathrm{~mm}, E=130 \mathrm{GPa}, K=500 \mathrm{Nm}$, and $G_{I C}=2006 \mathrm{~J} / \mathrm{m}^{2}$ ).
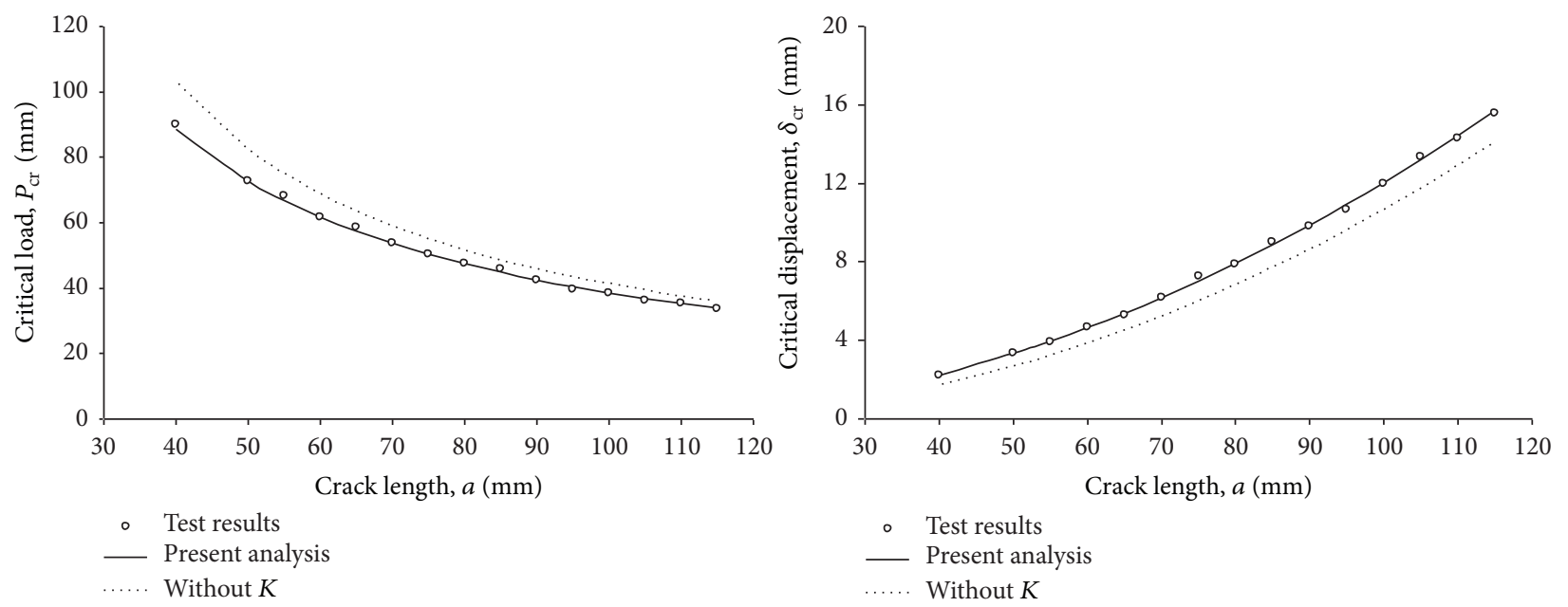

FIGURE 5: Comparison of experimental [8] and fracture analysis results of the critical load $\left(P_{\mathrm{cr}}\right)$ and the corresponding displacement $\left(\delta_{\mathrm{cr}}\right)$ with the crack length of unidirectional DCB specimens made of carbon/epoxy composites $(B=25 \mathrm{~mm}, 2 h=4.18 \mathrm{~mm}, E=136 \mathrm{GPa}, K=368 \mathrm{Nm}$, and $G_{I C}=263 \mathrm{~J} / \mathrm{m}^{2}$ ). 

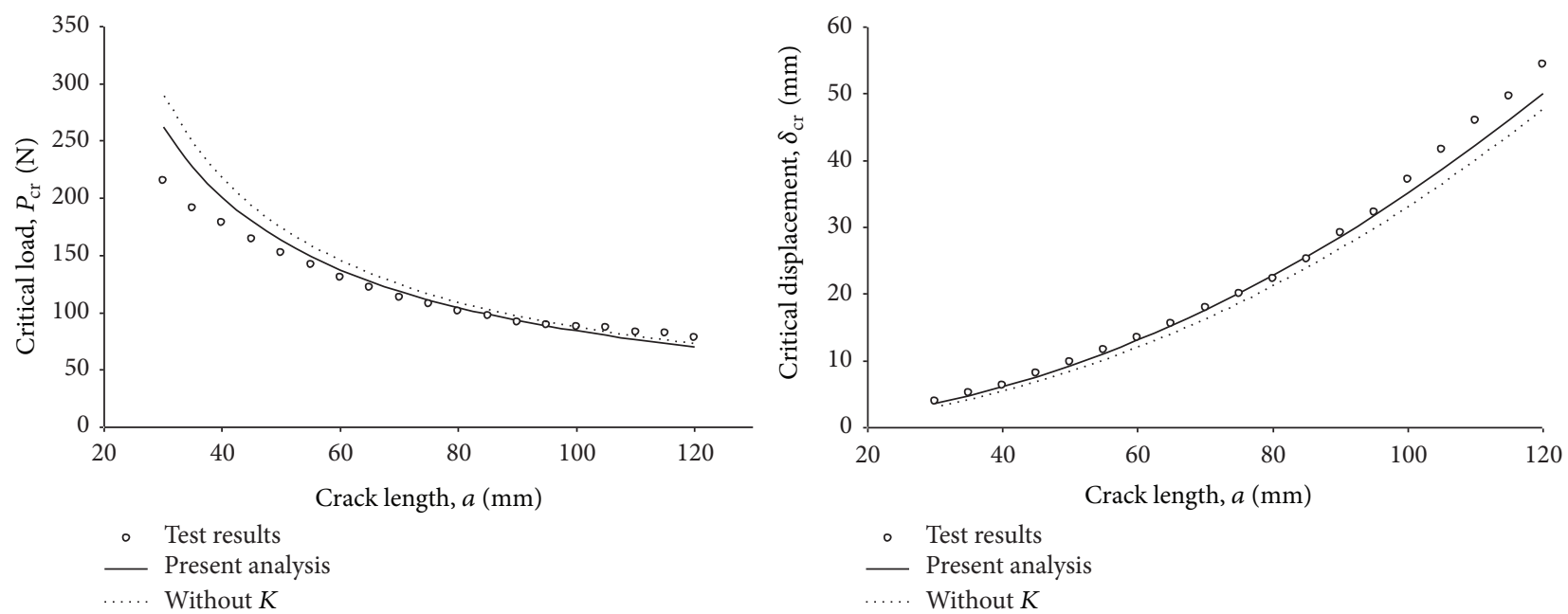

FiguRE 6: Comparison of experimental [18] and fracture analysis results of the critical load $\left(P_{\mathrm{cr}}\right)$ and the corresponding displacement $\left(\delta_{\mathrm{cr}}\right)$ with the crack length of unidirectional DCB specimens made of carbon/PES composites $(B=20 \mathrm{~mm}, 2 h=4.05 \mathrm{~mm}, E=127 \mathrm{GPa}, K=525 \mathrm{Nm}$, and $G_{I C}=2151 \mathrm{~J} / \mathrm{m}^{2}$ ).
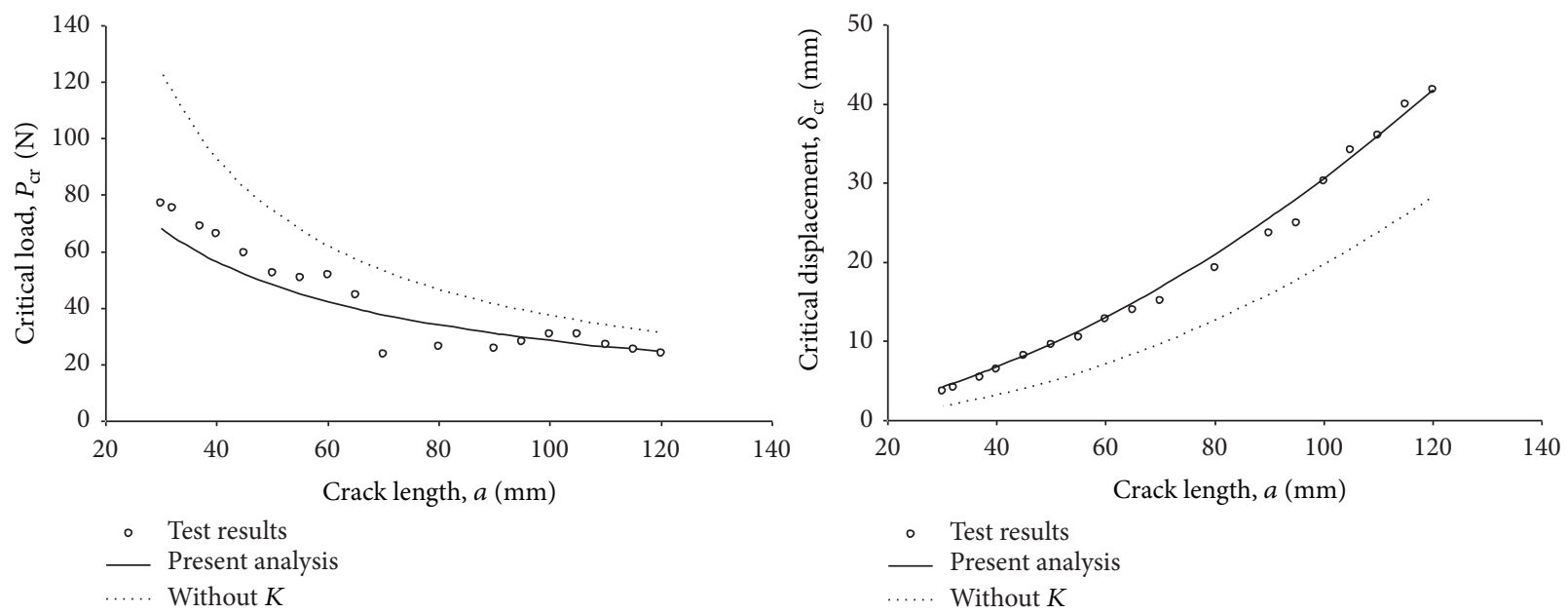

FIGURE 7: Comparison of experimental [19] and fracture analysis results of the critical load $\left(P_{\mathrm{cr}}\right)$ and the corresponding displacement $\left(\delta_{\mathrm{cr}}\right)$ with the crack length of unidirectional DCB specimens made of carbon/epoxy composites $(B=30 \mathrm{~mm}, 2 h=3 \mathrm{~mm}, K=37 \mathrm{Nm}, E=150 \mathrm{GPa}$, and $\left.G_{I C}=364 \mathrm{~J} / \mathrm{m}^{2}\right)$.

\section{Critical Load $\left(P_{\mathrm{cr}}\right)$ Estimates of DCB Specimens}

In order to examine the adequacy of the fracture toughness evaluation, fracture data [18-27] of the double cantilever beam (DCB) specimens on carbon-fiber/PEEK, carbon/polyether-sulphone, carbon/epoxy, and carbon/PEK$\mathrm{C}$ composites are considered. Fracture toughness $\left(G_{I C}\right)$ of the materials and estimates of the critical load for the DCB specimens are presented.

The critical load at the onset of delamination from the critical strain energy release rate is compared with the fracture data of the materials in Figures 4, 5, 6, 7, 8, 9, 10, 11, $12,13,14,15,16,17$, and 18 . The critical load estimates at the onset of delamination are found to be in good agreement with existing test results. For the case of large rotational stiffness, the difference in critical load estimates with and without considering $K$ will be insignificant.

It is observed from Figure 19 that the crack propagation in unidirectional laminate is stable along the length of specimen, whereas in the case of multidirectional laminates (with $+45^{\circ} /+45^{\circ}$ and $+45^{\circ} /-45^{\circ}$ interface) the crack growth is found to be zigzag because of fiber bridging.

\section{Conclusions}

This paper presents a simple and reliable relation for direct evaluation of delamination fracture toughness from the 

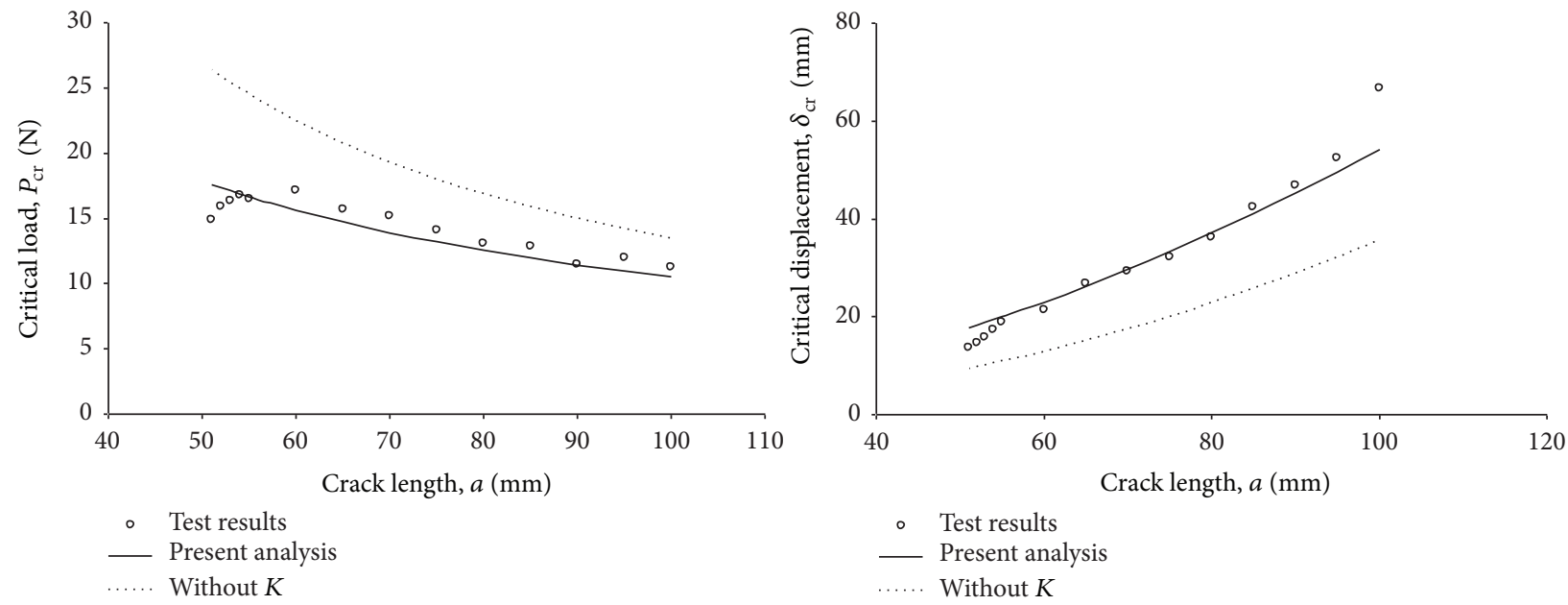

FIGURE 8: Comparison of experimental [20] and fracture analysis results of the critical load $\left(P_{\mathrm{cr}}\right)$ and the corresponding displacement $\left(\delta_{\mathrm{cr}}\right)$ with the crack length of unidirectional DCB specimens made of glass/epoxy composites $(B=25 \mathrm{~mm}, 2 h=3 \mathrm{~mm}, E=36 \mathrm{GPa}, K=8 \mathrm{Nm}$, and $\left.G_{I C}=286 \mathrm{~J} / \mathrm{m}^{2}\right)$.
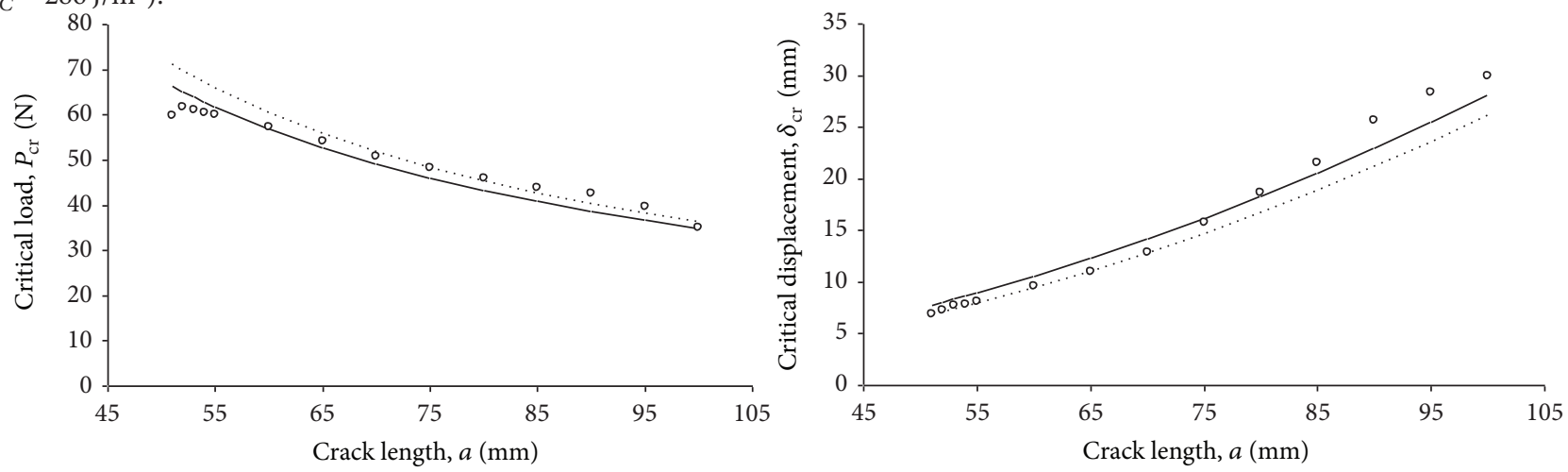

Test results
-
Present analysis

- Test results

— Present analysis

.... Without $K$

FiguRE 9: Comparison of experimental [21] and fracture analysis results of the critical load $\left(P_{\mathrm{cr}}\right)$ and the corresponding displacement $\left(\delta_{\mathrm{cr}}\right)$ with the crack length of unidirectional DCB specimens made of graphite/epoxy composites $(B=20 \mathrm{~mm}, 2 h=3.25 \mathrm{~mm}, E=130 \mathrm{GPa}, K=$ $238 \mathrm{Nm}$, and $G_{I C}=713 \mathrm{~J} / \mathrm{m}^{2}$ ).
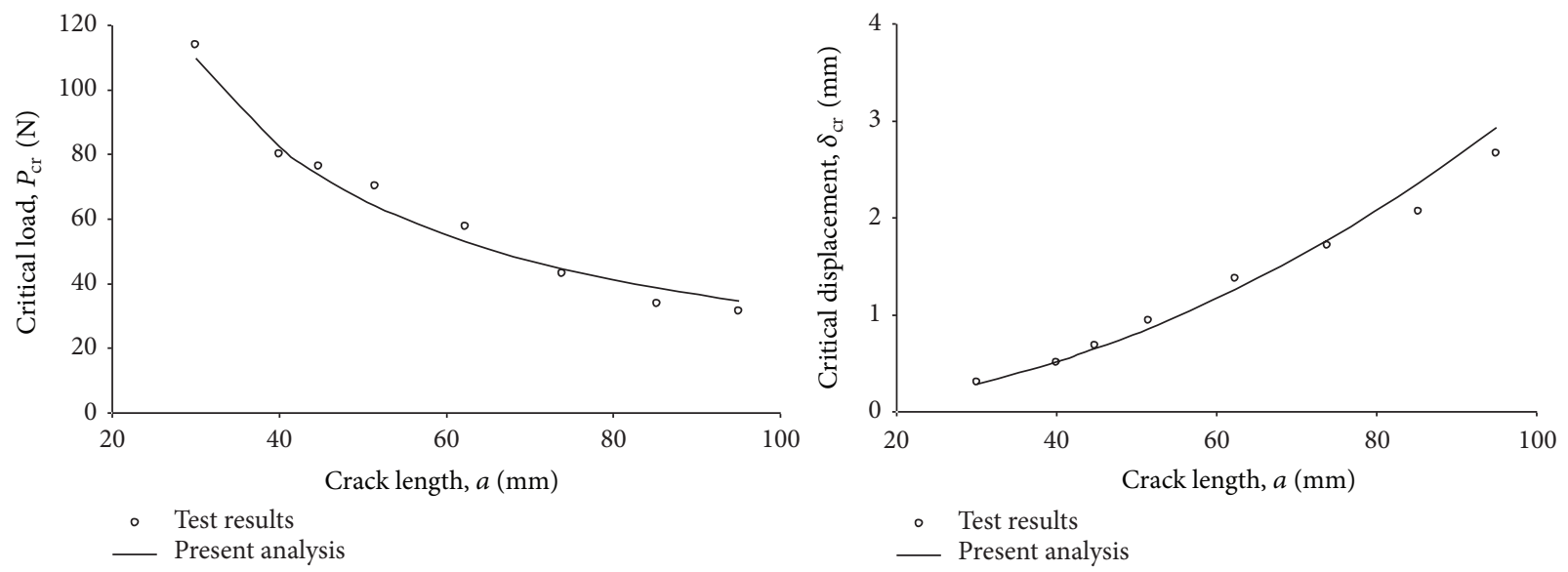

FIGURE 10: Comparison of experimental [22] and fracture analysis results of the critical load $\left(P_{\mathrm{cr}}\right)$ and the corresponding displacement $\left(\delta_{\mathrm{cr}}\right)$ with the crack length of unidirectional DCB specimens made of carbon/epoxy (T300/634DDS) composites $(B=2.5 \mathrm{~mm}, 2 \mathrm{~h}=12.5 \mathrm{~mm}, E=$ $133 \mathrm{GPa}, 1 / K \rightarrow 0$, and $\left.G_{I C}=642 \mathrm{~J} / \mathrm{m}^{2}\right)$. 

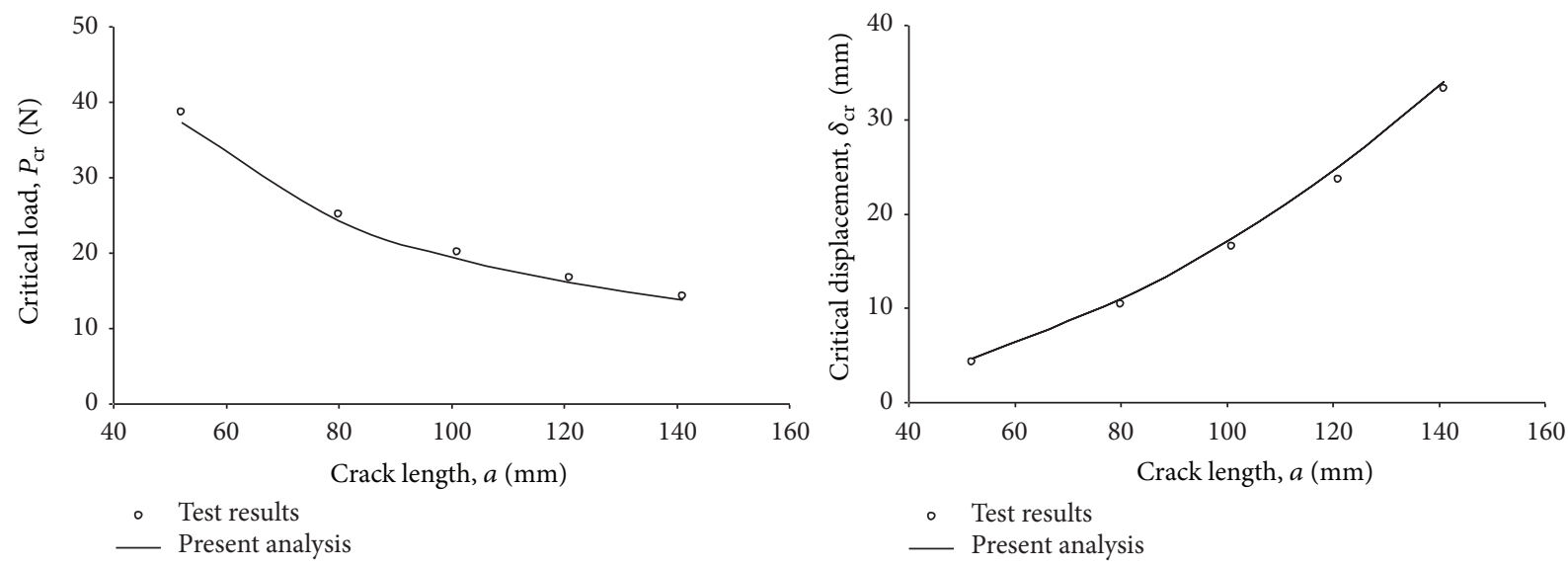

FIGURE 11: Comparison of experimental [23] and fracture analysis results of the critical load $\left(P_{\mathrm{cr}}\right)$ and the corresponding displacement $\left(\delta_{\mathrm{cr}}\right)$ with the crack length of unidirectional DCB specimens made of graphite/epoxy (CYCOM-982) composites $(B=19 \mathrm{~mm}, 2 \mathrm{~h}=3.04 \mathrm{~mm}, E=$ $136 \mathrm{GPa}, 1 / K \rightarrow 0$, and $\left.G_{I C}=262 \mathrm{~J} / \mathrm{m}^{2}\right)$.
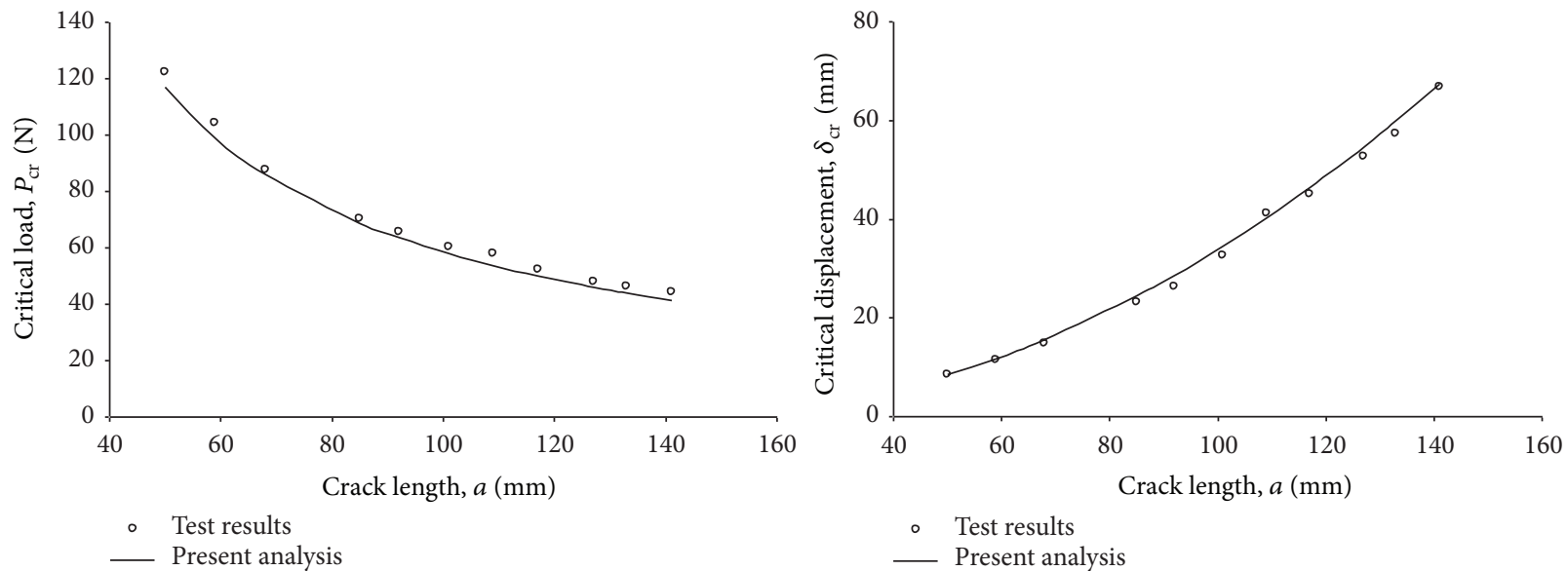

FIGURE 12: Comparison of experimental [23] and fracture analysis results of the critical load $\left(P_{\mathrm{cr}}\right)$ and the corresponding displacement $\left(\delta_{\mathrm{cr}}\right)$ with the crack length of unidirectional DCB specimens made of graphite/PEEK (APC-2) composites $(B=19 \mathrm{~mm}, E=129 \mathrm{GPa}, 1 / K \rightarrow 0$, and $G_{I C}=1564 \mathrm{~J} / \mathrm{m}^{2}$ ).
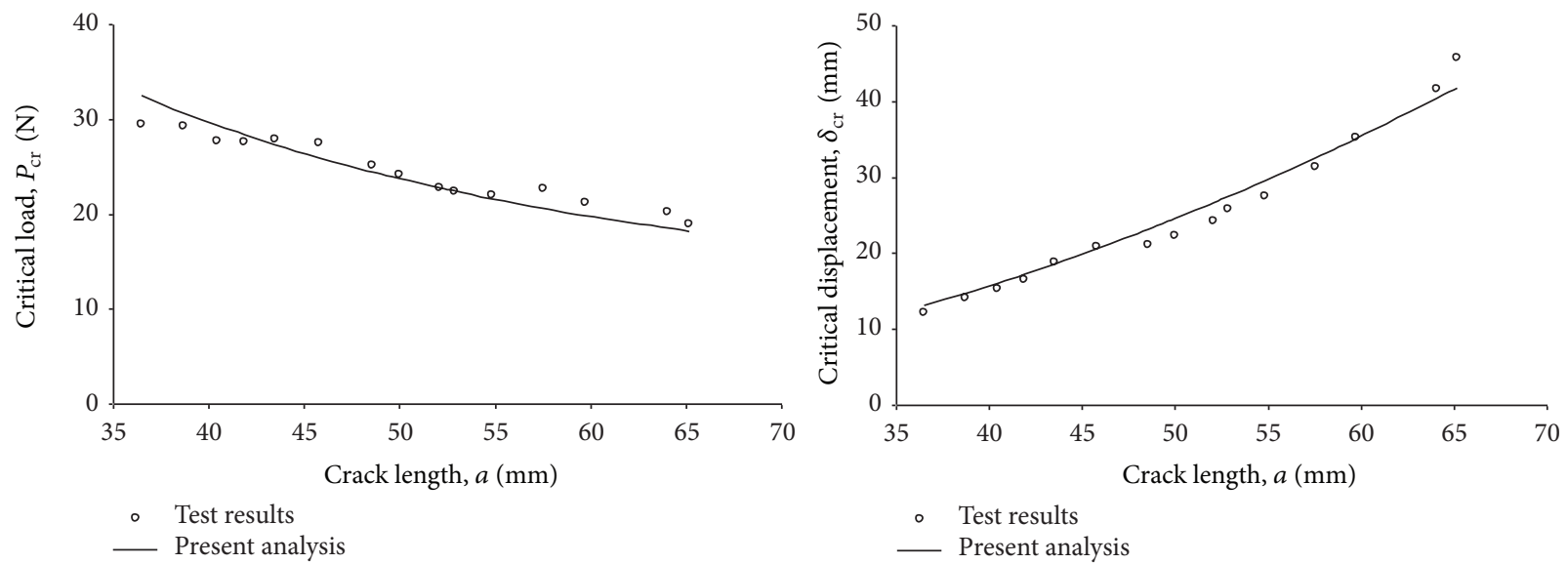

FIGURE 13: Comparison of experimental [24] and fracture analysis results of the critical load $\left(P_{\mathrm{cr}}\right)$ and the corresponding displacement $\left(\delta_{\mathrm{cr}}\right)$ with the crack length of unidirectional DCB specimens made of carbon/PEK-C composites $(B=20 \mathrm{~mm}, 2 h=2 \mathrm{~mm}, E=48.2 \mathrm{GPa}, 1 / K \rightarrow 0$, and $G_{I C}=863 \mathrm{~J} / \mathrm{m}^{2}$ ). 

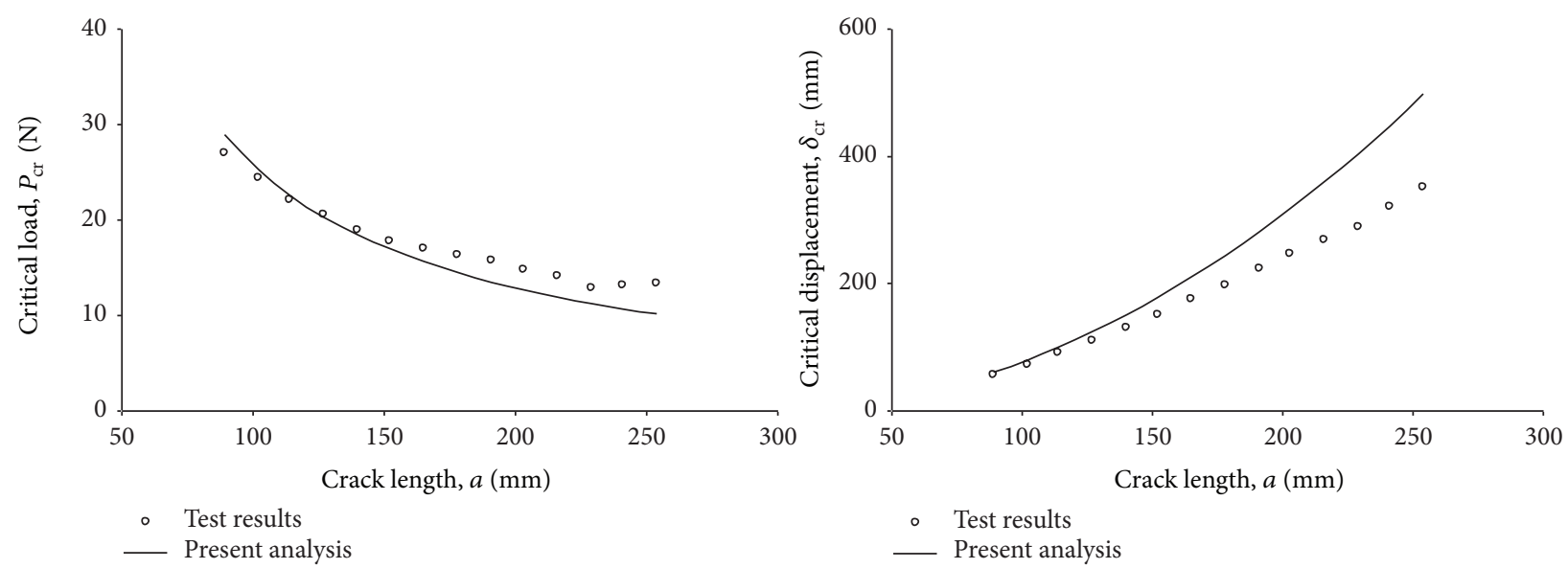

FIGURE 14: Comparison of experimental [25] and fracture analysis results of the critical load $\left(P_{\mathrm{cr}}\right)$ and the corresponding displacement $\left(\delta_{\mathrm{cr}}\right)$ with the crack length of unidirectional DCB specimens made of glass/epoxy composites $(B=25.4 \mathrm{~mm}, 2 h=2.59 \mathrm{~mm}, E=48.5 \mathrm{GPa}, 1 / \mathrm{K} \rightarrow 0$, and $G_{I C}=1176 \mathrm{~J} / \mathrm{m}^{2}$ ).
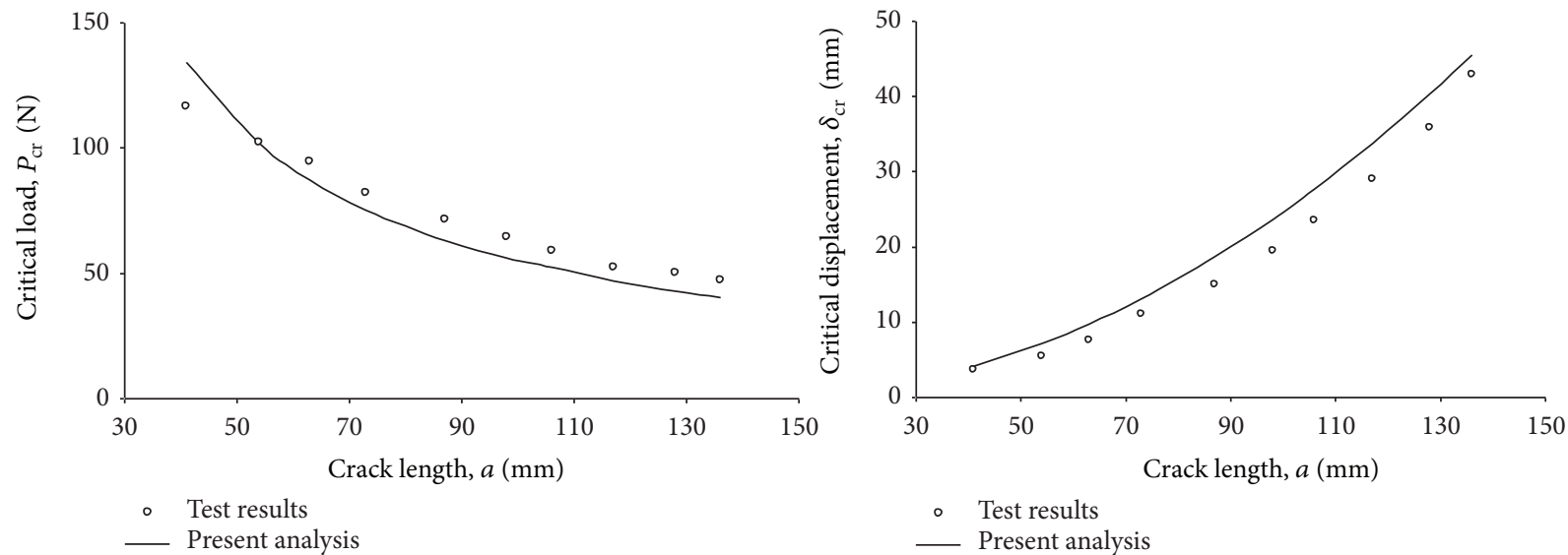

FiguRE 15: Comparison of experimental [26] and fracture analysis results of the critical load $\left(P_{\mathrm{cr}}\right)$ and the corresponding displacement $\left(\delta_{\mathrm{cr}}\right)$ with the crack length of unidirectional DCB specimens made of glass/polyester composites $(B=20 \mathrm{~mm}, 2 h=6 \mathrm{~mm}, E=33 \mathrm{GPa}, 1 / K \rightarrow 0$, and $G_{I C}=1018 \mathrm{~J} / \mathrm{m}^{2}$ ).
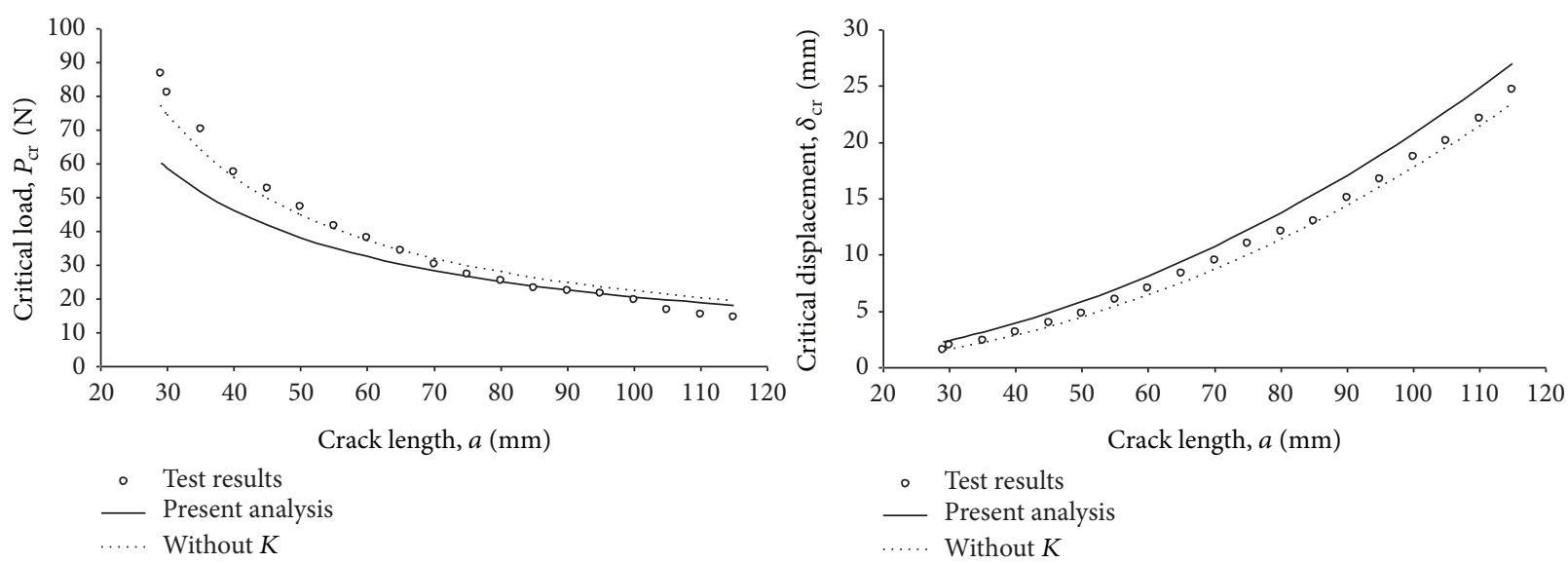

FIGURE 16: Comparison of experimental [27] and fracture analysis results of the critical load $\left(P_{\mathrm{cr}}\right)$ and the corresponding displacement $\left(\delta_{\mathrm{cr}}\right)$ with the crack length of DCB specimens made of carbon/epoxy (XAS-913C, Ciba Geigy plc) composites (lay-up: $\left[0^{\circ}\right]_{24}, B=20 \mathrm{~mm}, 2 h=$ $3 \mathrm{~mm}, E=150 \mathrm{GPa}, K=90.4 \mathrm{Nm}$, and $\left.G_{I C}=297 \mathrm{~J} / \mathrm{m}^{2}\right)$. 

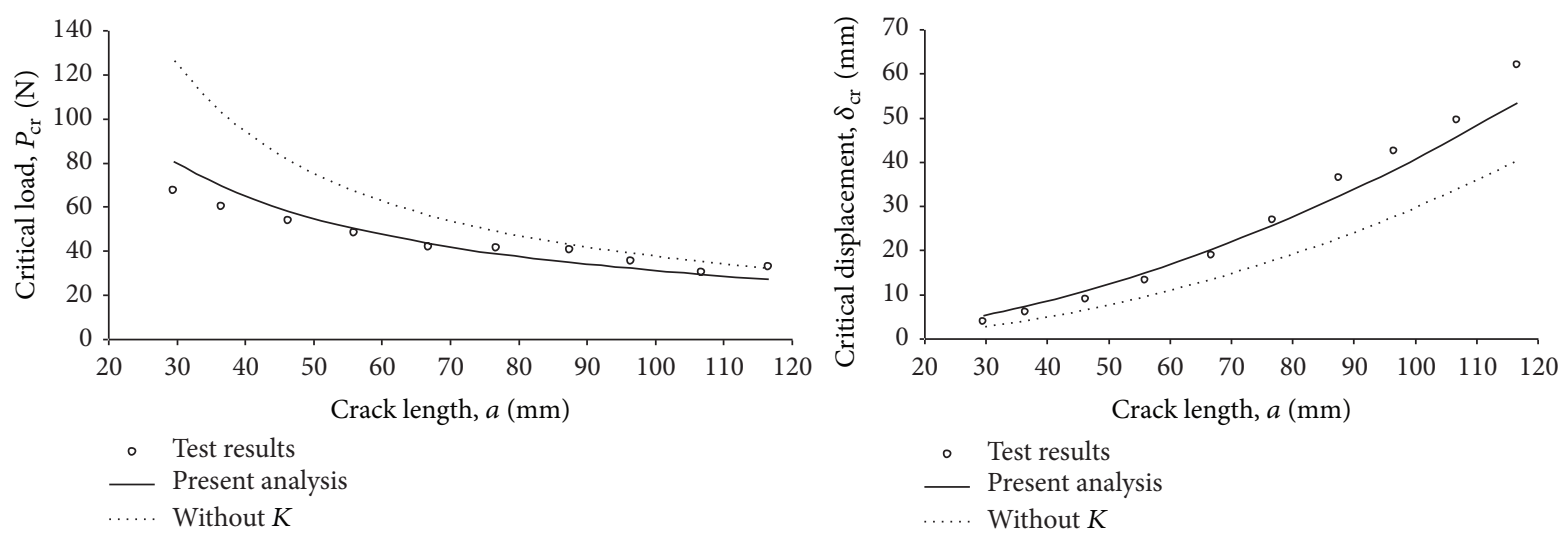

Figure 17: Comparison of experimental [27] and fracture analysis results of the critical load $\left(P_{\mathrm{cr}}\right)$ and the corresponding displacement $\left(\delta_{\mathrm{cr}}\right)$ with the crack length of DCB specimens made of carbon/epoxy (XAS-913C, Ciba Geigy plc) composites (lay-up: $\left[-45^{\circ} / 0^{\circ} /\left(+45^{\circ}\right)_{2} / 0^{\circ} /-45^{\circ} /+45^{\circ} / 0^{\circ} /\left(-45^{\circ}\right)_{2} / 0^{\circ} / 45^{\circ}\right]_{s}, B=20 \mathrm{~mm}, 2 h=3 \mathrm{~mm}, E=150 \mathrm{GPa}, K=39 \mathrm{Nm}$, and $\left.G_{I C}=831 \mathrm{~J} / \mathrm{m}^{2}\right)$.
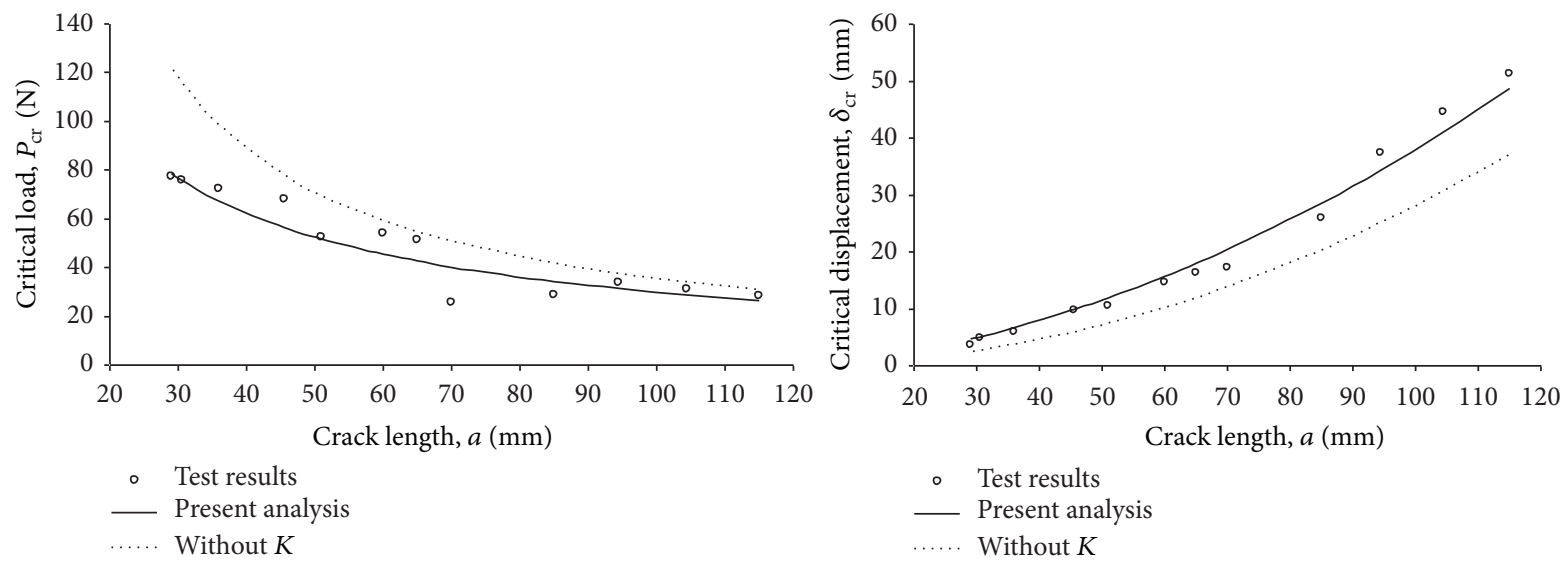

Figure 18: Comparison of experimental [27] and fracture analysis results of the critical load $\left(P_{\text {cr }}\right)$ and the corresponding displacement $\left(\delta_{\mathrm{cr}}\right)$ with the crack length of DCB specimens made of carbon/epoxy (XAS-913C, Ciba Geigy plc) composites (lay-up: $\left[-45^{\circ} / 0^{\circ} /\left(+45^{\circ}\right)_{2} / 0^{\circ} /-45^{\circ} /+45^{\circ} / 0^{\circ} /\left(-45^{\circ}\right)_{2} / 0^{\circ} / 45^{\circ}\right]_{2}, B=20 \mathrm{~mm}, 2 \mathrm{~h}=3 \mathrm{~mm}, E=150 \mathrm{GPa}, K=41 \mathrm{Nm}$, and $\left.G_{I C}=742 \mathrm{~J} / \mathrm{m}^{2}\right)$.

fracture data of composite DCB specimens. The critical load estimates of DCB specimens from the evaluated $G_{I C}$ are found to be in good agreement with in-house and existing test results of different composites. This study clearly demonstrates the effect of root rotation at the crack-tip of the DCB specimen on the critical fracture toughness evaluation. However, if the rotational spring stiffness is very large (i.e., $1 / K \rightarrow 0$ ), the crack-tip behaves like built-in support and the critical load of (9) coincides with the results of simple cantilever beam theory (see Figures 10 to 15).

It is noted from Figures 4 to 9 and Figures 16 to 18 that cantilever beam theory overestimates the critical load and underestimates deflection of the test results. The multidirectional laminates (with $+45^{\circ} / 45^{\circ}$ and $+45^{\circ} /-45^{\circ}$ interfaces) show higher fracture energy than the unidirectional one.

\section{Nomenclature}

$a: \quad$ Crack length

$a_{o}: \quad$ Initial crack length

$A, m$ : Constants in power-law

$B: \quad$ Width of the DCB specimen

$C$ : Compliance of the specimen

DCB: Double cantilever beam

$E_{11}$ : Longitudinal tensile modulus

$G_{I C}:$ Fracture toughness or critical strain energy release rate

$G_{I R}:$ Strain energy release rate at any point

$2 h: \quad$ Specimen thickness

$K$ : $\quad$ Rotational spring stiffness at the crack-tip

$n: \quad$ Number of fracture data 


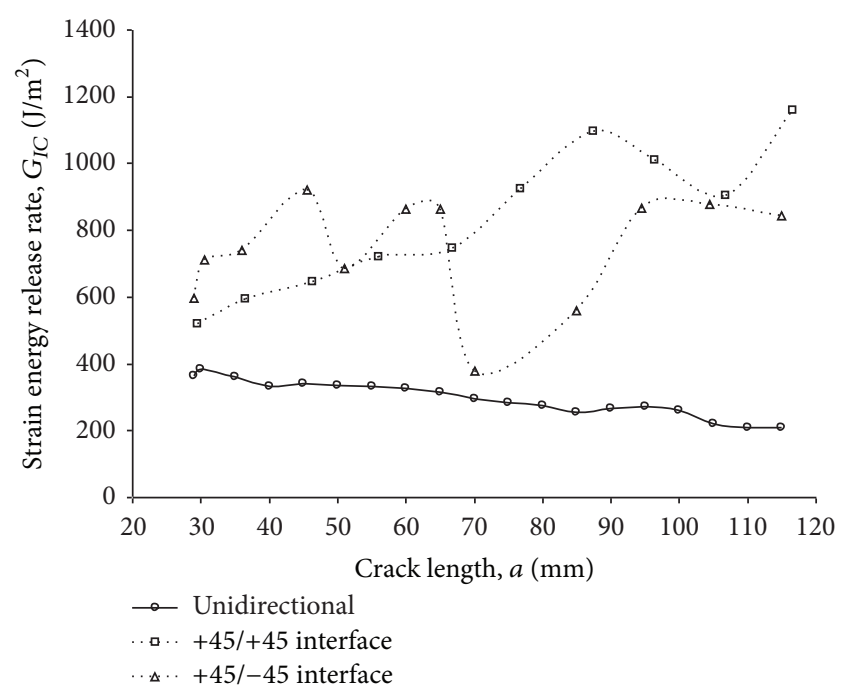

Figure 19: Comparison of R-curves [27] of DCB specimens with different stacking sequence made of carbon/epoxy (XAS-913C, Ciba Geigy plc).

$P$ : Applied load on both sides of the specimen

$\delta$ : Crack mouth opening displacement.

\section{Conflict of Interests}

The authors declare that there is no conflict of interests regarding the publication of this paper.

\section{References}

[1] I. E. A. Aghachi and E. R. Sadiku, "Integrity of glass/epoxy Aircraft composite part Repaired using five different Methods," International Journal of Engineering Science and Technology, vol. 5, no. 1, pp. 1-15, 2013.

[2] P. K. Mallick, Fiber-Reinforced Composites: Materials, Manufacturing, and Design, Taylor \& Francis, New York, NY, USA, 3rd edition, 2007.

[3] R. Krueger, "Computational fracture mechanics for composites state of the art and challenges," Prediction and Modelling of Failure Using FEA, Copenhagen/Roskilde, Denmark, 2006.

[4] T. H. Walker, L. B. Ilcewicz, D. R. Polland, and C. C. Poe Jr., "Tension fracture of laminates for transport fuselage. Part II: large notches," in Proceedings of the 3rd NASA/ DoD ACT Conference, vol. 2, pp. 727-758, 1992, NASA CP-3178.

[5] T. H. Walker, L. B. Ilcewicz, D. R. Polland, J. B. Bodine, and C. C. Poe Jr., "Tension fracture of laminates for transport fuselage. Part III: structural configurations," in Proceedings of the 4th NASA Advanced Composite Technology Conference, NASA CP3229, part 1, pp. 863-880, 1993.

[6] J. T. Wang, C. C. Poe Jr., D. R. Ambur, and D. W. Sleight, "Residual strength prediction of damaged composite fuselage panel with R-curve method," Composites Science and Technology, vol. 66, no. 14, pp. 2557-2565, 2006.

[7] R. F. Gibson, Principles of Composite Material Mechanics, CRC Press, Taylor \& Francis, New York, NY, USA, 2010.
[8] S. Hashemi, A. J. Kinloch, and J. G. Williams, "Corrections needed in double-cantilever beam tests for assessing the interlaminar failure of fibre-composites," Journal of Materials Science Letters, vol. 8, no. 2, pp. 125-129, 1989.

[9] B. Nageswara Rao and A. R. Acharya, "Evaluation of fracture energy GIC using a double cantilever beam fibre composite specimen," Engineering Fracture Mechanics, vol. 51, no. 2, pp. 317-322, 1995.

[10] B. N. Rao and A. R. Acharya, "Maximum load at the initiation of delamination growth in a double cantilever beam specimen," Materials Research and Advanced Techniques, vol. 86, no. 6, pp. 428-433, 1995.

[11] D. Broek, Elementary Engineering Fracture Mechanics, Martinus Nijhoff, Dordrecht, The Netherlands, 1986.

[12] A. Korjakin, R. Rikards, F.-G. Buchholz, H. Wang, A. K. Bledzki, and A. Kessler, "Comparative study of interlaminar fracture toughness of GFRP with different fiber surface treatments," Polymer Composites, vol. 19, no. 6, pp. 793-806, 1998.

[13] V. A. Franklin and T. Christopher, "Fracture energy estimation of DCB specimens made of glass/epoxy: an experimental study," Advances in Materials Science and Engineering, vol. 2013, Article ID 412601, 7 pages, 2013.

[14] V. A. Franklin and T. Christopher, "Generation and validation of crack growth resistance curve from DCB specimens: an experimental study," Strength of Materials, vol. 45, no. 6, pp. 674-683, 2013.

[15] F.-G. Buchholz, R. Rikards, and H. Wang, "Computational analysis of interlaminar fracture of laminated composites," International Journal of Fracture, vol. 86, no. 1-2, pp. 37-57, 1997.

[16] ASTM Standard D5528-94a, "Standard test method for mode I interlaminar fracture toughness of unidirectional continuous fiber reinforced polymer matrix composites," Philadelphia, Pa, USA, 1994.

[17] R. A. Naik, J. H. Crews Jr., and K. N. Shivakumar, "Effects of Ttabs and large deflections in DCB specimen tests," in Composite Materials, Fatigue and Fracture, T. K. O'Brien, Ed., vol. 3 of ASTM STP 111, pp. 169-186, American Society for Testing and Materials, 1991.

[18] S. Hashemi, A. J. Kinloch, and J. G. Williams, "Mechanics and mechanisms of delamination in a poly(ether sulphone)-fibre composite," Composites Science and Technology, vol. 37, no. 4, pp. 429-462, 1990.

[19] V. Q. Bui, E. Marechal, and H. Nguyen-Dang, "Imperfect interlaminar interfaces in laminated composites: delamination with the R-curve effect," Composites Science and Technology, vol. 60, no. 14, pp. 2619-2630, 2000.

[20] B. F. Sørensen, K. Jørgensen, T. K. Jacobsen, and R. C. Østergaard, "DCB-specimen loaded with uneven bending moments," International Journal of Fracture, vol. 141, no. 1-2, pp. 163-176, 2006.

[21] Agostino, Simulation of delamination in composite materials under static and fatigue loading by cohesive zone models [Ph.D. thesis], 2007-2008.

[22] L. Ye, "Evaluation of Mode-I interlaminar fracture toughness for fiber-reinforced composite materials," Composites Science and Technology, vol. 43, no. 1, pp. 49-54, 1992.

[23] J. W. Gillespie Jr., L. A. Carlsson, R. B. Pipes, R. Rothschilds, B. Trethewey, and A. Smiley, Delamination Growth in Composite Materials, NASA-CR 178066, 1986.

[24] J. Zhou, T. He, B. Li, W. Liu, and T. Chen, "A study of mode I delamination resistance of a thermoplastic composite," 
Composites Science and Technology, vol. 45, no. 2, pp. 173-179, 1992.

[25] D. F. Devitt, R. A. Schapery, and W. L. Bradley, "A method for determining mode I delamination fracture toughness of elastic and viscoelastic composite materials," Journal of Composite Materials, vol. 14, pp. 270-285, 1980.

[26] A. Szekrényes and J. Uj, "Advanced beam model for fiberbridging in unidirectional composite double-cantilever beam specimens," Engineering Fracture Mechanics, vol. 72, no. 17, pp. 2686-2702, 2005.

[27] P. Robinson and D. Q. Song, "Modified DCB specimen for Mode I testing of multidirectional laminates," Journal of Composite Materials, vol. 26, no. 11, pp. 1554-1577, 1992. 

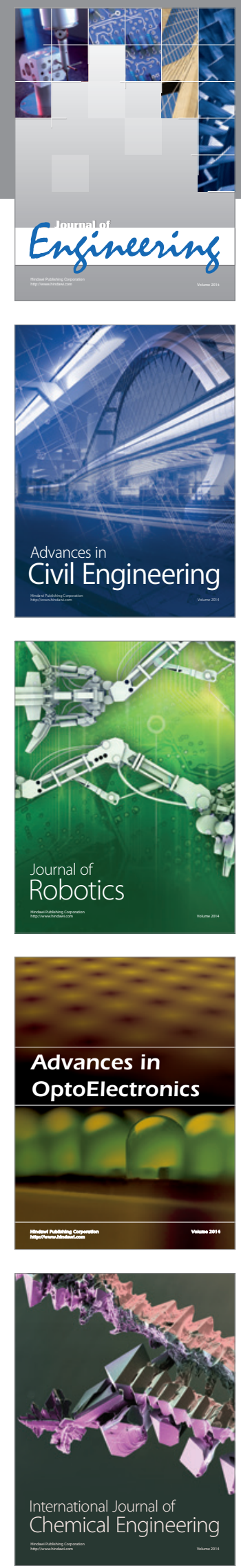

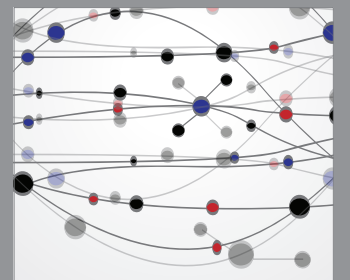

The Scientific World Journal
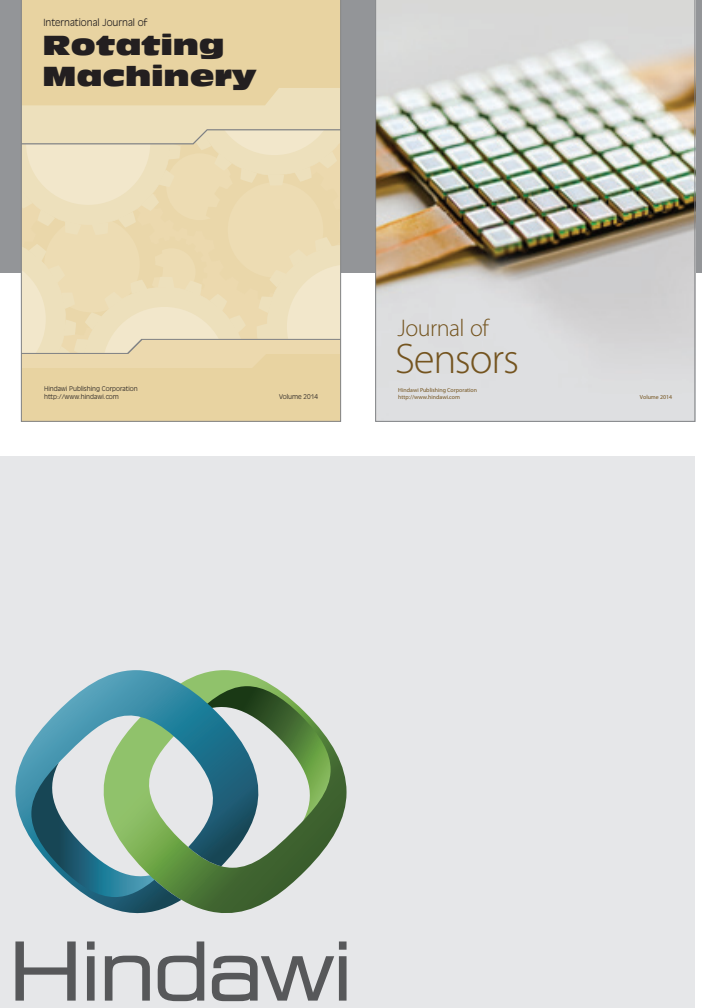

Submit your manuscripts at http://www.hindawi.com
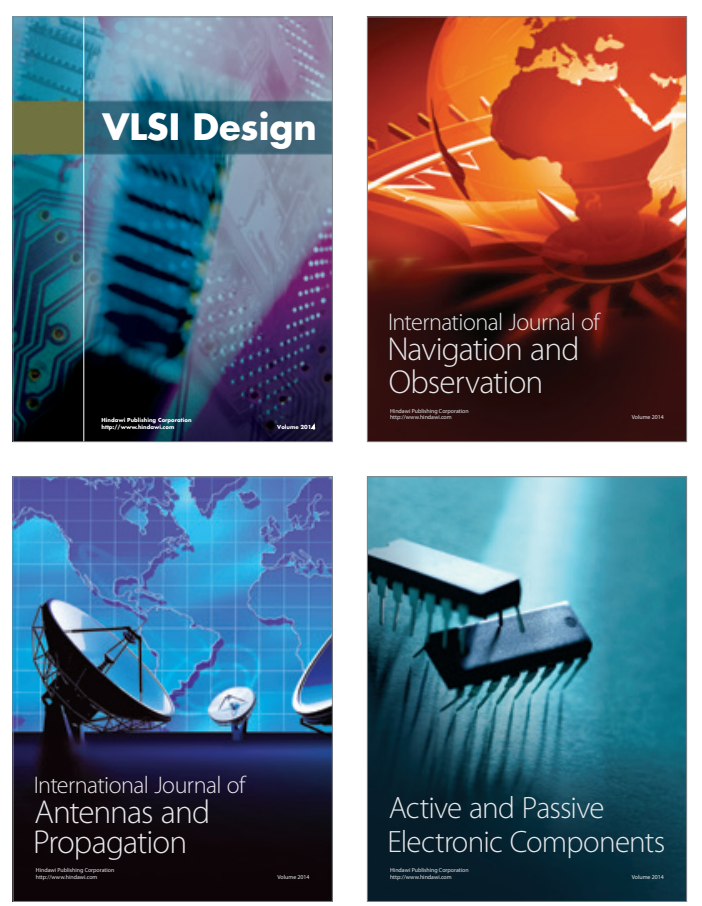
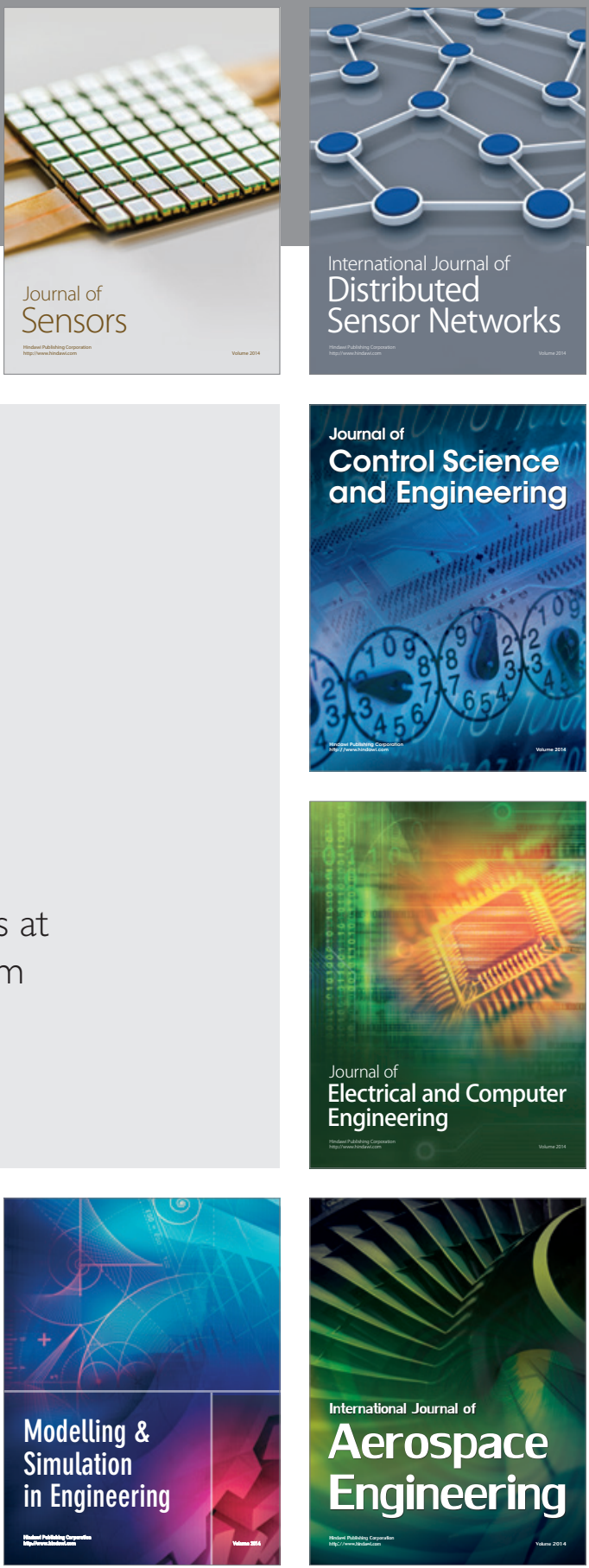

Journal of

Control Science

and Engineering
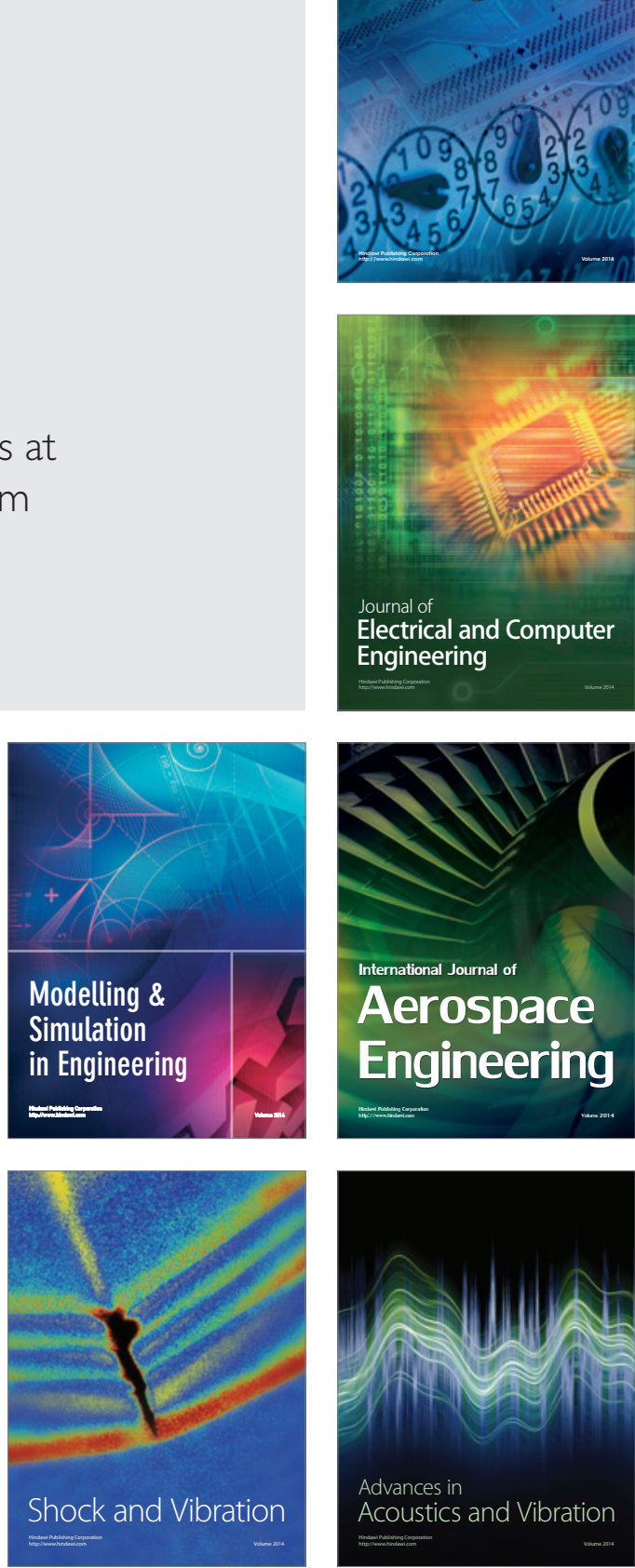